\title{
CALCULATED ASSESSMENT OF CONTACT STRENGTH, WEAR AND RESOURCE OF METAL-POLYMER GEARS MADE OF DISPERSION- REINFORCED COMPOSITES
}

UDC: 539.538:539.621

Original scientific paper

https://doi.org/10.18485/aeletters.2021.6.2.2

\author{
Myron Chernets ${ }^{1}$, Serge Shil'ko ${ }^{2}$, Anatolii Kornienko ${ }^{1 *}$ \\ ${ }^{1}$ National Aviation University, Kyiv, Ukraine \\ ${ }^{2}$ The State Scientific Institution "V.A. Belyi Metal-Polymer Research Institute of National Academy of \\ Sciences of Belarus", Gomel, Belarus
}

\begin{abstract}
:
The method of calculating the wear and life of gears with metal wheels is used to analyze the bearing capacity and tribotechnical characteristics of metal-polymer gears with wheels made of a dispersion-reinforced composite - polyamide filled with dispersed carbon and glass fibers. Taking into account the pairing of the engagement, the maximum contact pressures at the beginning of the transmission operation were estimated, as well as their changes due to wear of the teeth of the composite wheels upon reaching acceptable wear. It was established that the degree of change in initial pressures due to wear substantially depends on the gear material and, in the case of a composite gear, a significant decrease is observed at the gear input. The linear wear of the working profile of the teeth and the localization of its maximum values are determined. It is shown that the estimated transmission resource with a carbon composite gear is more than eight times higher than that with a glass-filled polyamide gear. This parameter is largely determined by the operating conditions of the master and slave transmission links. The resource of the "steel gearcomposite wheel" pair is about 2.4 times the resource of the "composite gear-steel wheel" pair. The best option is "steel gear-carbon-filled polyamide wheel", because its resource for wear is 20 times greater than that of the transmission "glass-filled polyamide gear-steel wheel".
\end{abstract}

\section{ARTICLE HISTORY}

Received: 16.04.2021.

Accepted: 23.06.2021.

Available: 30.06.2021.

\section{KEYWORDS}

Metal-polymer gears, antifriction composites, glass and carbon fillers, contact pressures, method of calculating wear, resource

\section{INTRODUCTION}

Metal-polymer gears are widely used in mechanical engineering, instrumentation and other industries. However, it should be noted that the methods for calculating the wear and life of metal-polymer gears with wheels of dispersionreinforced polymeric materials are not sufficiently developed. The calculation of the resource during wear of a cylindrical gear with a polyamide wheel reinforced with glass or carbon fibers is described only in [1], under the assumption of a linear dependence of abrasive wear on the friction path [2]. A significant effect of the volumetric content of the filler is predicted on the contact pressure in the engagement, wear and resource of the transmission.

In the literature [3-5], partial results of calculating the contact and bending strength of metal-polymer (MP) spur gears are given. So in $[3,4]$, the effect of the load distribution between the gears on the contact and bending stresses in a MP spur gears with a polyamide PA66 gear was studied. Accordingly, in [5], an assessment of the 
maximum contact pressures and sliding speeds for gears made of polyamide PA6 and steel S355J2 was carried out.

A certain number of works are devoted to the experimental study of model MP gears or polymer materials on friction test machines [6 - 9]. For pairs of gear materials, steel S355 - polyamide PA6-Mg, PA6-Na, PA66GF30, polyoxylene POM-S in $[6,7]$ volumetric wear of teeth without and with abrasive were studied experimentally. The weight wear of a gear made of PA6 paired with a steel gear for different types of metal-polymer gear trains (spur, bevel, worm) was studied in [10]. Tribological properties of different types of polymer composites, including polyacetal PA6, were investigated in [11] on a pin-on-disk testing machine under dry friction. In [12], the tribological properties of polyamide PA6 under dry friction at different conditions were investigated according to the steel pin - rotating polymer disk scheme. The tribological behavior of PA6 was investigated experimentally according to the pin-on-disk scheme in [13]. The wear resistance of PA66 and steel SAE 1045 used in clutch discs was studied in [14].

Data on experimental studies of the wear of polymer composite materials used in metalpolymer gears $[1,8,9]$ indicate that their destruction during friction without lubrication occurs by the fatigue rather than the abrasive wear mechanism. However, methods for calculating gears with metal wheels [2,15-22] are also based on the Arhard abrasive law of wear, although this type of wear is practically not observed in the absence of an abrasive medium. Such a simplified description of the wear kinetics can be used only with dry friction in the presence of an abrasive medium. In this regard, the urgent problem is the development of effective methods for calculating the wear and life of both metal-polymer and conventional gears, taking into account the real mechanisms of the process of their wear.

A method for calculating the bearing capacity and tribotechnical characteristics of various (spur and helical cylindrical and bevel, as well as worm) gears is presented in [24-27] on the assumption of a fatigue wear mechanism. The application of this method to assess the contact strength, wear and life of the gear metal-polymer from antifriction polymer composites - polyamides filled with dispersed carbon and glass fibers, was shown in $[29,30]$. In this article, it is used to further investigate such gears, taking into account additional factors.

\section{MATHEMATICAL MODEL OF SLIDING WEAR}

In the author's phenomenological model of surface destruction of materials during sliding friction (wear) it is assumed that wear occurs as a result of frictional fatigue under the action of friction forces arising in tribocontact. This is evidenced by the numerous results of triboexperimental studies presented in the literature and author's research. The following linear differential equations system is used to describe wear kinetics [23-27]:

$$
\frac{1}{v} \frac{d h_{1}}{d t}=\Phi_{1}^{-1}(\tau), \quad \frac{1}{v} \frac{d h_{2}}{d t}=\Phi_{2}^{-1}(\tau) .
$$

where $\tau=f p$.

Experimental values of the wear-resistance function are approximated by the relation

$$
\Phi_{k}(\tau)=C_{k}\left(\frac{\tau_{S}}{\tau}\right)^{m_{k}}
$$

where $\tau_{S}=R_{0,2} / 2 ; R_{0,2}=0,7 R_{m}$.

The wear resistance experimental function $\Phi_{i}\left(\tau_{i}\right)$ of a gear teeth material is determined in the following way

$$
\Phi_{i}\left(\tau_{i}\right)=L / h_{i} .
$$

Taking into account relation (2) after separation of variables and system integration (1) on condition that $\tau=f p=$ const, the following dependence will arise

$$
t_{k}=\frac{C_{k}}{v}\left(\frac{\tau_{s}}{\tau}\right)^{m_{k}} h_{k} .
$$

Then, the function of linear wear of gear teeth at an arbitrary point $j$ of the working tooth flank surface over a period $t_{j}$ of their interaction has been determined as

$$
h_{k}=\frac{v t_{k}}{C_{k}}\left(\frac{\tau}{\tau_{S}}\right)^{m_{k}} .
$$

\section{RESEARCH METHOD}

It is known that sliding friction with rolling occurs in gears engagement. The highest sliding speed is achieved at the entrance and exit of the teeth from the meshing, and at the pitch point it is zero.

To determine the teeth linear wear at an arbitrary point $j$ of the working tooth flank surface 
at $n$ gear revolutions, taking into account the conditions of contact interaction of the teeth in engagement, formula (5) will be [25]:

$$
h_{k j n}^{\prime}=\frac{v_{j} t_{j h}^{\prime}\left(f p_{j h \max }\right)^{m_{k}}}{C_{k}\left(0.5 R_{m}\right)^{m_{k}}} .
$$

Sliding speed $v_{j}$ is determined by the dependence:

$$
v_{j}=\omega_{1} r_{b 1}\left(\operatorname{tg} \alpha_{1 j}-\operatorname{tg} \alpha_{2 j}\right)
$$

where $r_{b 1}=r_{1} \cos \alpha, \alpha_{1 j}, \alpha_{2 j}$ according to $[25,26]$.

Due to wear, the radii of curvature of the working tooth profiles increase, which leads to a decrease in the initial maximum contact pressures $p_{j \max }$ and an increase in the width $2 b_{j}$ of the contact area. Accordingly, the current values of $p_{j h \max }$ and $2 b_{j h}$ are calculated by the Hertz formulas modified in $[25,26]$ taking into account the pairing of the mesh:

$$
p_{j h \max }=0.564 \sqrt{N^{\prime} \theta / \rho_{j h}}, 2 b_{j h}=2.256 \sqrt{\theta N^{\prime} \rho_{j h}},
$$

where $N^{\prime}=N / b w ; N=9550 P / r_{1} n_{1} \cos \alpha$;

$$
\theta=\left(1-\mu_{1}^{2}\right) / E_{1}+\left(1-\mu_{2}^{2}\right) / E_{2} ; \rho_{j h}=\frac{\rho_{1 j h} \rho_{2 j h}}{\rho_{1 j h}+\rho_{2 j h}} \text {. }
$$

At the end of each cycle of gearing of teeth $n=$ 1 (one revolution of the gear), it is necessary to take into account changes in all the calculated contact parameters, which leads to a large amount of calculations. To reduce it, a block calculation scheme is used, in which the correction of the radii of curvature of the tooth profiles, maximum contact pressures and the width of the contact area is performed after a certain number of revolutions (interactions block). The resulting change in the parameters is calculated as the product of the changes in one cycle of the teeth interacting with the factor $B$. In the next block, the accumulated changes are taken into account according to formula (10) and further calculations are carried out according to the specified values of these parameters, which continue until the specified allowable wear of the teeth of one of the wheels in specified contact point. A technique for accounting for changes in the initial radii of curvature $\rho_{k j}$ of the teeth during wear is presented in [24]:

$$
\rho_{k j h}=\rho_{k j}+\tilde{E}_{k} \sum_{B_{1}}^{B_{\max }} D_{k j B} K_{k j B}^{-1}
$$

where the block value equal to the number of gear revolutions is selected depending on the expected duration of the transmission as follows: $B=1$ (exact solution), $B=n_{1}$ (1 $\left.\mathrm{min}\right), B=60 n_{1}$ (1 hour), $B=600 n_{1}$ (10 hours), $B=6000 n_{1}$ (100 hours), etc.

Here, $\tilde{E}_{k}$ is the constant, depending on the permissible wear $h_{k *}$ of the teeth and taking on value $\tilde{E}_{1 c}=1,5, \tilde{E}_{2 c}=320$ for fiberglass and $\tilde{E}_{1 y}=4, \tilde{E}_{2 y}=320$ carbon fiber, respectively.

The change in the curvature of the tooth profiles due to wear during each block is determined as follows:

$$
K_{k j B}=8 \sum^{B} h_{k j n}^{\prime} / l_{k j}^{2}
$$

The values $h_{k j n}^{\prime}$ are calculated in each subsequent revolution over time $t_{j h}^{\prime}=2 b_{j h} / v_{0}$, and the variable width of the contact area $2 b_{j h}$ at the $n_{k}-1$ revolution or at the $(B-1)^{\text {th }}$ block is set according to (8).

The length of the chord $l_{k j}$ of a circle approximating the involute between points $j-1, j$ +1 is determined as follows:

$$
l_{k j}=2 \rho_{k j h} \sin \varepsilon_{k j h}=\text { const , }
$$

where $S_{k j}=\left|\frac{m z_{k}}{4}\left(\frac{1}{\cos ^{2} \alpha_{k j}}-\frac{1}{\cos ^{2} \alpha_{k, j+1}}\right) \cos \alpha\right|$, $\varepsilon_{k j h}=S_{k j} / \rho_{k j h}$.

Therefore, after each interaction (block of interactions), all calculated parameters change, in particular, $h_{1 j}, h_{2 j}, \rho_{1 j h}, \rho_{2 j h}, \rho_{j h}, p_{j h \max }, 2 b_{j h} . t_{j h}^{\prime}$.

For the adopted frequency of rotation of the gear $n_{1 s}$ and wheel $n_{2 s}$, which corresponds to a given number of blocks, the total wear $h_{1 j n}$ and $h_{2 j n}$ of teeth at the $j$ contact point is determined by summing:

$$
h_{1 j n}=\sum_{1}^{n_{1 s}} h_{1 j B}, h_{2 j n}=\sum_{1}^{n_{2 s}} h_{2 j B},
$$

where $n_{2 s}=n_{1 s} / u ; h_{k j B}=\sum h_{k j}^{\prime}$.

The of the transmission work $t$ for the number of revolutions $n_{1 s}$ or $n_{2 s}$ of the gears at which permissible wear of the teeth of one of them is achieved, is calculated as follows:

$$
t=n_{1 s} / 60 n_{1}=n_{2 s} / 60 n_{2} .
$$


Since the transmission implements two - one two-pair gearing, respectively, the angles of transition from two-pair $\left(\Delta \varphi_{1 F_{2}}\right)$ to single-pair gearing and again to two-pair $\left(\Delta \varphi_{1 F_{1}}\right)$ gearing, as well as the angle of the teeth coming out $\Delta \varphi_{1 E}$ of gearing in a cylindrical spur gear, are set in accordance with the recommendations $[23,26]$.

\section{NUMERICAL SOLUTION, RESULTS AND DISCUSSION}

Two variants of a cylindrical metal-polymer gear transmission with straight involute teeth were considered: direct one - "steel gear - composite wheel" $(G(S)-W(C))$, reverse one - "composite gear-steel wheel" (G(C)-W(S)).

Wheel materials are:

1) steel 45 in the delivery state (GOST 105088), grinding, $E=2,1 \cdot 10^{5} \mathrm{MPa}, \mu=0.3 ; C_{1}=10^{9}, m_{1}$ $=2$ according to [28];

2) carbon-filled polyamide UPA (T) - 6/30 (TU RB 03535279.049-99), $E_{y}=5.2 \mathrm{GPa}, \mu_{y}=0.42, C_{y}=$ $4.7 \cdot 10^{6}, m_{y}=2.3$ [28]; the volumetric content of the filler is $30 \%$;

3) glass-filled polyamide PA6-LT-SV30-1 (TU RB 500048054.020-2001), $E_{c}=3.9 \mathrm{GPa}, \mu_{c}=0.42, C_{c}$ $=1.2 \cdot 10^{6}, m_{c}=1.9[28]$; the volumetric content of the filler is $30 \%$.

The initial data for the calculation are: $T_{\text {nom }}=$ $4000 \mathrm{Nmm}, n_{1}=1000 \mathrm{rpm} ; B=600$ thousand revolutions (10 hours of operation); $K_{g}=1.2 ; m=4$ $\mathrm{mm}, u=3, z_{1}=20, z_{2}=60, b=50 \mathrm{~mm}, f_{c}=f_{y}=0.3$; $h_{k^{*}}=0.5 \mathrm{~mm}, \varepsilon_{\alpha}=1.372$.

The calculation results are presented in Fig. 1-4. In particular, the diagram in Fig. 1 shows the change in the initial maximum contact pressures $p_{j \max }$ in engagement for the full cycle of tooth interaction, and the change in maximum contact pressures $p_{j h \max }$ due to wear of the teeth of the composite gear to an acceptable value is shown in Fig. 2.

Contact pressure $p_{j \max }$ in the first (initial) phase of two-pair gearing will be significantly higher than that in its third (final) phase, and one in the second (intermediate) phase with one-pair gearing higher than that with two-pair gearing. The highest contact pressure in the mesh occurs at the entrance to the single-pair mesh, which exceeds the stress at the entrance to the two-pair mesh ( $p$. 0 ) by $8 \%$ and in the pole (point $P-\Delta \varphi=13.08^{\circ}$ ) by $12.7 \%$. The pressure $p_{j \max }$ in the entire range of variation of the angle of rotation $\Delta \varphi$ of the gear in a gear with a wheel made of carbon-filled polyamide is higher than that in a gear with a wheel made of glass-filled polyamide.

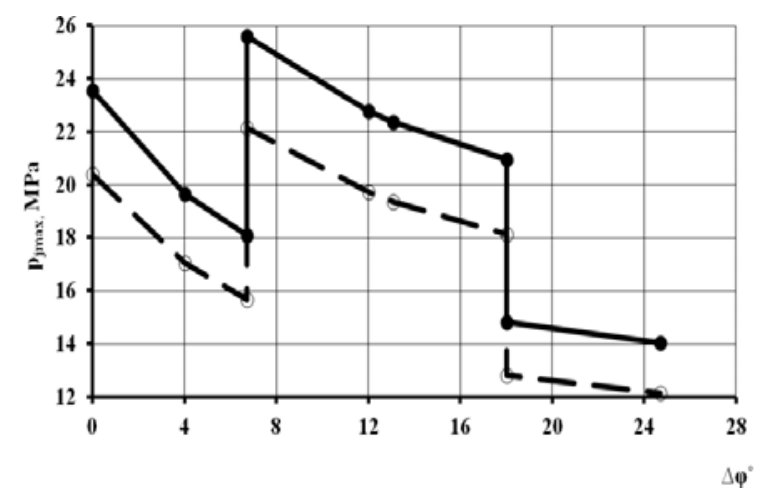

Fig. 1. Maximum contact pressure in engagement: dashed line (unfilled markers) - glass-filled composite; solid line (filled markers) - carbon-filled composite

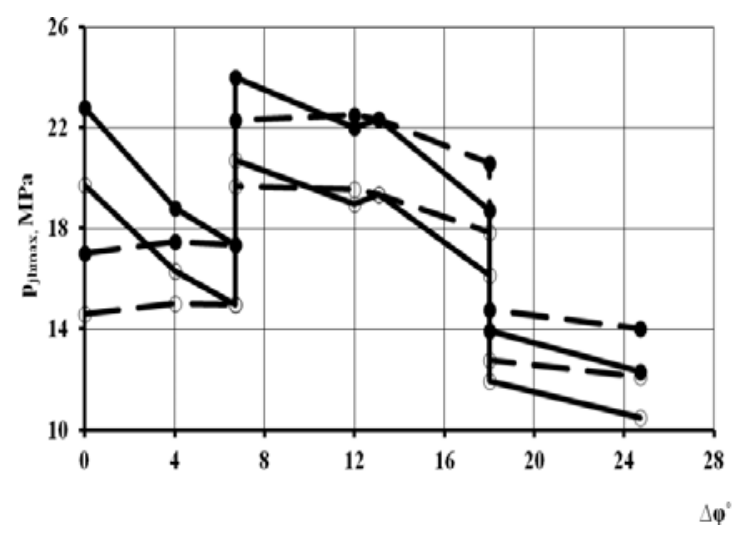

Fig. 2. Maximum contact pressures in engagement: solid lines $-G(S)-W(C)$ gear, dashed lines $-G(C)-W(S)$ gear, the designations are the same as in Fig. 1

The wear of the teeth of the composite wheel in the $G(S)-W(C)$ gear leads to a moderate (5-6\%) reduction $p_{j \max }$, and in the $\mathrm{G}(\mathrm{C})-\mathrm{W}(\mathrm{S})$ gear, the wear of the teeth of the composite gear quite noticeably reduces the pressure in the first gearing zone, especially at the entrance to two-pair gearing (up to 28\%). The pressures in the transmission $\mathrm{G}(\mathrm{S})-\mathrm{W}(\mathrm{C})$ at the entrance to the two-pair and single-pair gears, as well as at the gearing pole are quite close.

Linear wear $h_{1 j}, h_{2 j}$ of the working tooth profiles of the composite gear and wheel, respectively, is shown in Fig. 3. 


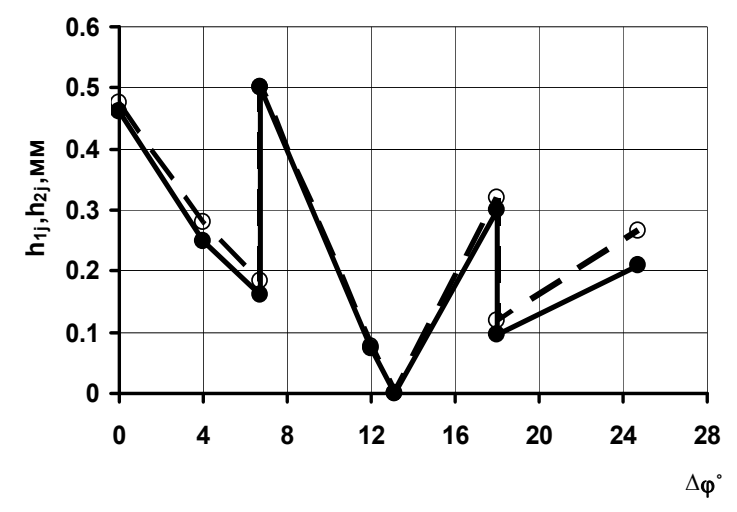

Fig. 3. Distribution of linear gear wear in gearing: dashed line (unfilled markers) - glass-filled composite; solid line (filled markers) - carbon-filled composite

At the entrance to the two-pairs engagement $(\Delta \varphi=0)$ there is a significant teeth wear, which is slightly lower than permissible wear and which decreases until the transition of the teeth into single-pair engagement $\left(\Delta \varphi \approx 6.69^{\circ}\right)$. At the point of entry of the teeth into the single-pair engagement, the permissible wear is achieved the fastest in comparison with other points on the working profile. Further, the teeth wear in the pitch point $\left(\Delta \varphi=13.08^{\circ}\right)$ will practically decrease to zero, because there the sliding speed is zero. As the sliding speed increases, the wear increases again until the teeth come out of the single-pair engagement $\left(\Delta \varphi=18^{\circ}\right)$. At transition to the twopairs engagement it falls to the minimum. Later, when the gear rotates, it increases slightly again until the teeth come out of the two-pairs engagement. It should be noted that the wear of steel teeth is approximately three orders of magnitude less than the wear of composite gear teeth. Almost equal wear of composite wheels is achieved at the entrance to two-pairs and singlepair engagement.

The significant difference in the wear resistance of the gears $G(C)-W(S)$ and $G(S)-W(C)$ is explained by the different (taking into account the gear ratio) loading frequency of the teeth of the metal wheel and composite gear, as well as increased wear of the latter as a result of increased heat generation.

The effect of the material of the gears of the transmission on the nature of the change in the initial maximum contact pressures $p_{j \max }$ due to wear of the teeth of the composite wheels is shown in Fig. 4.

As noted earlier, contact pressures $p_{j h \text { max }}$ undergo relatively small changes in all phases of gearing in gears $G(S)-W(C)$, and there is a particularly significant transformation in the first phase of gearing, which for both types polyamide composites are clearly visible in the figures in gears $\mathrm{G}(\mathrm{C})-\mathrm{W}(\mathrm{S})$.

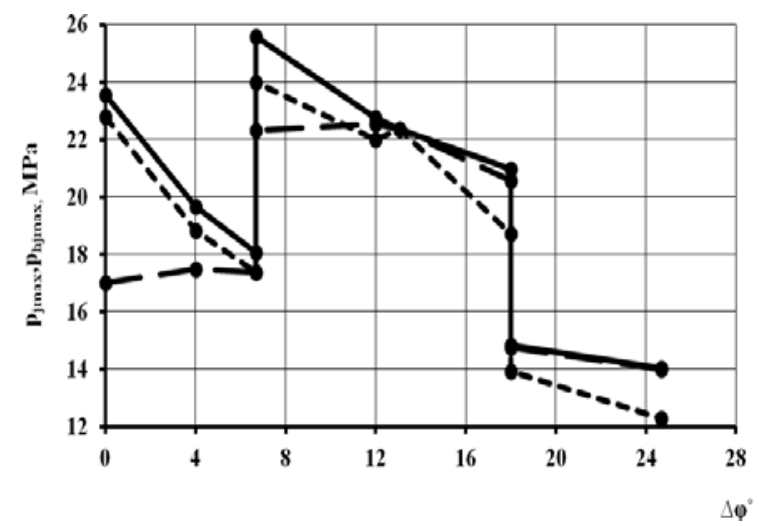

a)

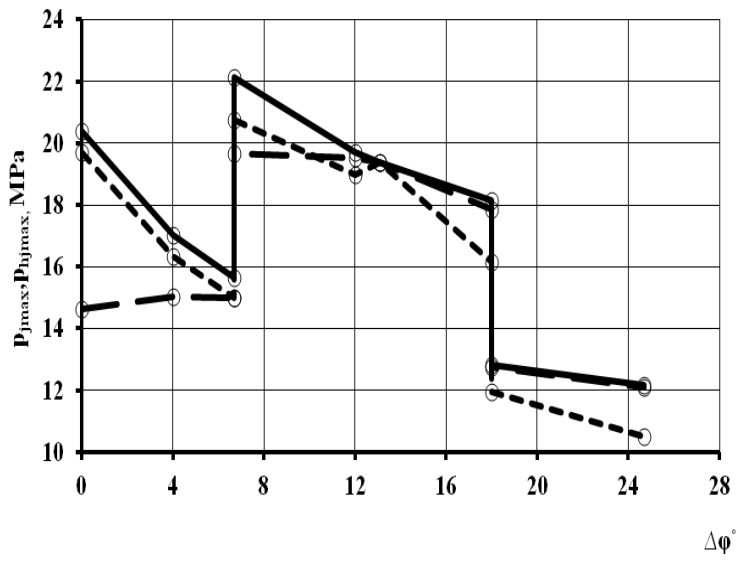

b)

Fig. 4. Change in maximum contact pressure $p_{\text {jmax }}$ in engagement: a) a carbon fiber wheel, b) a fiberglass wheel; the solid lines are the pressures $p_{\text {jmax }}$, the dotted lines are $p_{\text {jmax }}$ in the $\mathrm{G}(\mathrm{S})-\mathrm{W}(\mathrm{C})$ gears, the dashed lines are $p_{\text {jmax }}$ in the $\mathrm{G}(\mathrm{C})-\mathrm{W}(\mathrm{S})$ gears

The results of calculating the resource $t_{B \min }^{(y)}$, $t_{B \min }^{(c)}$ at the input of the teeth in single-pair gearing of the considered transmission options for carbon and fiberglass are given below.

1) $\mathrm{G}(\mathrm{S})-\mathrm{W}(\mathrm{C}): t_{B \min }^{(y)}=157950$ hours, $t_{B \min }^{(c)}=$ 19200 hours; $t_{B \min }^{(y)} / t_{B \min }^{(c)}=8.23$.

2) $\mathrm{G}(\mathrm{C})-\mathrm{W}(\mathrm{S}): t_{B \min }^{(y)}=64650$ hours, $t_{B \min }^{(c)}=7900$ hours; $t_{B \min }^{(y)} / t_{B \min }^{(c)}=8.18$.

The application of the developed calculation method allows us to predict a very significant (more than eight-fold) change in the transmission resource depending on the use of the composite for the manufacture of the driving or driven gears. The results obtained indicate that the resource of the transmission of $G(C)-W(S)$ will be 
approximately 2.4 times less than that the transmission of $\mathrm{G}(\mathrm{S})-\mathrm{W}(\mathrm{C})$. The relative wear resistance of the used polymer composite materials is indicated by the ratio of $C_{\mathrm{y}} / C_{\mathrm{c}}=3.92$. The optimal choice of the design of the adopted metal-polymer gear for the specified operating conditions and a polyamide reinforced composite for one of the wheels allows us to increase its resource by about 20 times - from 7900 to 157950 hours.

\section{CONCLUSIONS}

According to the research, the following conclusions are made:

1. The method developed previously for calculating gears with metal wheels [23-26] can be effectively used to calculate the bearing capacity, wear and resource of metal-polymer gears with wheels made of dispersion-filled polymer composites.

2. The initial maximum contact pressures $p_{j \max }$ in a gear with a carbon fiber wheel are approximately $13.5 \%$ higher than that in a gear with a fiberglass wheel.

3. The initial maximum contact pressures $p_{j \max }$ at the two most loaded points - at the input of the teeth into single-pair and two-pair engagement (Fig. 1) - are differ insignificantly (1.08 times).

4. The initial maximum contact pressures in the pole of engagement are lower than those at the entrance to single-pair engagement by $13 \%$. Therefore, in standardized methods for calculating gears, where contact stresses are calculated in the gearing pole, the maximum level of the latter is significantly underestimated.

5. There is a fundamental difference in the degree of influence of the wear of the teeth of the composite wheels on the magnitude of the contact pressures $p_{j \max }$ in the engagement (Fig. 2 and 4). While for a steel gear, this change is insignificant (up to 6\%) in the entire cycle of tooth interaction, the wear of the teeth of the composite gear causes a significant decrease in pressure in the initial gearing zone and, in particular, at the entrance to two-pair gearing (up to $28 \%$ ).

6. As a result of wear of the composite wheels, the pressure difference $p_{j h \max }$ at the pole and at the entrance to the single-pair and two-pair engagement is insignificant (Fig. 2 and 4).

7. The greatest wear of composite wheels is achieved at two gearing moments - at the entrance to a single-pair (allowable wear) and close to it in magnitude - at the entrance to the phase of two-pair gearing (Fig. 3).

8. The resource of the studied metal-polymer gears with a composite carbon fiber wheel is more than 8 times higher than the resource of the fiberglass wheel.

9. The resource of the transmission with a steel gear and a composite wheel is approximately 2.5 times higher than that of the pairs "composite gear - steel wheel".

10. The predicted transmission resource under the specified operating conditions varies widely from 7900 to 157950 hours, i.e., 20 times, for the studied polyamide composites and the options for choosing a composite gear wheel as a drive or driven one.

\section{NOMENCLATURE}

$h_{1}, h_{2}$ is the linear wear of tribocoupling elements; $t$ is the wear time;

$\Phi(\tau)$ is the characteristic function of wear resistance of the material;

$\tau$ is the specific friction force arising in tribocontact;

$f$ is the sliding friction coefficient;

$t$ is the time of wear;

$v$ is the sliding velocity;

$p$ is the maximum tribocontact pressure;

$C_{k}, m_{k}$ are the indicators of resistance to wear of tribological pair materials;

$k=1 ; 2$ is the wheel numbering ( 1 - gear, 2 gear wheel);

$k$ is the number of elements in the tribosystem.

$\tau_{S}$ is the shear strength of a material;

$R_{0,2}$ is the conventional yield strength of a material under tension;

$R_{m}$ is the tensile strength of a material.

$h_{i}$ is the linear wear of material samples;

$L$ is the sliding path;

$i=1,2,3, \ldots$ are loading steps;

$t_{j h}^{\prime}$ is the wear time of the teeth when moving the contact point $j$ along the tooth contour by the width of the contact area $2 b_{j h}$, which is changed due to wear during one revolution of the gear;

$v_{0}=\omega_{1} r_{1} \sin \alpha$ is the displacement speed of the contact point along the tooth contour;

$\omega_{1}$ is the rotation gear angular speed;

$v_{j}$ is the sliding speed; 
$p_{j h \max }$ is the current maximum pressure at the point of contact $j$;

$j=0,1,2,3, \ldots$ is the contact point number of tooth working surfaces;

$N$ is the geared force;

$b$ is the wheel width;

$P$ is the drive shaft power;

$w$ is the number of pairs of gear teeth;

$E, \mu$ are the Young's modulus and Poisson's ratio of wheel material;

$r_{1}$ is the gear pitch radius;

$n_{1}$ is the gear speed;

$\alpha$ is the profile angle;

$\rho_{1 j h}, \rho_{2 j h}$ are the radii of curvature of the tooth profiles that are changed due to wear in the normal section of the gear and wheel, respectively;

$B_{1}$ and $B_{\max }$ are the first and last blocks of calculations, respectively;

$B$ is the calculation block size

$\tilde{E}_{k}$ is the constant depending on permissible wear $h_{k *}$ of the teeth;

$D_{k j B}=K_{k j B}^{2}$ is the dimensionless parameter whose values are constant within one block;

$\varepsilon_{k j h}$ is the angle between points $j$ and $j+1$;

$S_{k j}$ is the involute length between points $j, j+1$, $\alpha_{k j}, \alpha_{k, j+1}$ are the engagement angles for involute points $j, j+1$;

$m$ is the engagement module;

$z_{1}, z_{2}$ are the number of gear teeth and wheels;

$h_{k j B}$ is the tooth wear in each block;

$u$ is the gear ratio;

$T_{\text {nom }}$ is the rated torque;

$K_{g}$ is the dynamic factor;

$E_{y}, E_{c}$ are the elastic moduli of carbon and fiberglass, respectively;

$\mu_{y}, \mu_{c}$ are the Poisson's ratios of carbon and fiberglass, respectively;

$\Delta \varphi$ is the angle of rotation of the gear teeth from the point of initial contact ( 0 ) to point 1 , etc.;

$\varepsilon_{\alpha}$ is the overlap coefficient;

$t_{B \min }^{(y)}, t_{B \min }^{(c)}$ are the minimum values of durability of gears with carbon and fiberglass wheels, respectively.

\section{REFERENCES}

[1] S.V. Shilko, V.E. Starzhinskii, Prediction of Wear Resistance of Gearing with Wheels
Made of Reinforced Composites. J. of Friction and Wear, 14 (3), 1993: 7-13,

[2] Yu.N. Drozdov, To the Development of Methods for Calculating the Wear and Modeling of Friction. In book: Wear resistance. Nauka, Moscow, 1975 (in Russian).

[3] C.J. Hooke, S.N. Kukureka, P. Liao, M. Rao, Y.K. Chen, The Friction and Wear of Polymers in Non-Conformal Contacts. Wear, 200 (1-2), 1996: 83-94.

https://doi.org/10.1016/S0043-1648(96)07270-5

[4] G. Kalacska, M. Kozma, P. De Baets, R. Keresztes, L. Zsidai, Friction and Wear of Engineering Polymer Gears, Proc. of WTC 2005. World Tribology Congress III, September, 2005, Washington, D.C., USA, pp.259-260.

https://doi.org/10.1115/WTC2005-63961

[5] R. Keresztes, G. Kalacska, Friction of Polymer/Steel Gear Pairs. Plastics and Rubber, 45, 2008: 236-242.

[6] J. Sukumaran, M. Ando, P. De Baets, V. Rodriguez, L. Szabadi, G. Kalacska, V. Paepegem, Modelling Gear Contact with TwinDisc Setup. Tribology International, 49, 2012: 1-7.

https://doi.org/10.1016/i.triboint.2011.12.007

[7] J. Cathelin, E. Letzelter., M. Guingand, J.P. De Vaujany, L. Chazeau, Experimental and Numerical Study a Loaded Cylindrical PA66 Gear. J. of Mechanical Design., 135, 2013: 8998.

https://doi.org/10.1115/1.4023634

[8] V.E. Starzhinskii, E.V. Shalobaev, S.V. Shil'ko, et al., Elements Drive Devices. Calculation, Design, Technologies / Ed. by Yu.M. Pleskachevsky. Belaruskaya navuka, Minsk, 2012 (in Russian).

[9] S.V. Shil'ko, V.E. Starzhinskii, E.M. Petrokovets, et al., Two-Level Calculation Method for Tribojoints Made of Dispersion-Reinforced Composites: Part 1. J. of Friction and Wear, 34(1), 2013: 65-69.

https://doi.org/10.3103/S1068366614010085

[10] S. Yousef, T.A. Osman, M. Khattab, A. A. Bahr, A. M. Youssef, A New Design of the Universal Test Rig to Measure the Wear Characterizations of Polymer Acetal Gears (Spur, Helical, Bevel, and Worm). Advances in Tribology, 2015, 2015: ID 926918.

https://doi.org/10.1155/2015/926918

[11] J. Jozwik, K. Dziedzic, M. Barszcz, M. Pashechko, Analysis and Comparative Assessment of Basic Tribological Properties of 
Selected Polymer Composites. Materials, 13(1), 2020: 75.

https://doi.org/10.3390/ma13010075

[12] A. Pogačnik, A. Kupec, M. Kalin, Tribological properties of polyamide (PA6) in self-mated contacts and against steel as a stationary and moving body. Wear, 378-379, 2017: 17-26.

https://doi.org/10.1016/j.wear.2017.01.118

[13] M.V. Kulkarni, K. Elangovan, K. Hemachandra Reddy, S.J. Basappa, Tribological behaviours of ABs and PA6 polymer metal sliding combinations under dry friction, water absorbed and electroplated conditions. Journal of Engineering Science and Technology, 11(1), 2016: 68-84.

[14]A.G. de A. Rosa, J. A. Moreto, M.D. Manfrinato, L.S.Rossino, Study on friction and wear behavior of SAE 1045 steel, reinforced nylon 6.6 and NBR rubber used in clutch disks. Mat. Res., 17(6), 2014:1397-1403.

https://doi.org/10.1590/1516-1439.282714

[15] J. Brauer, S. Andersson, Simulation of Wear in Gears with Flank Interference - a Mixed FE and Analytical Approach. Wear, 254, 2003: 1216-1232.

https://doi.org/10.1016/S0043-1648(03)00338-7

[16] A. Flodin, S. Andersson, Simulation of Mild Wear in Spur Gears. Wear, 207 (1-2), 1997: 16-23.

https://doi.org/10.1016/S0043-1648(96)07467-4

[17] A. Flodin, S. Andersson, Wear Simulation of Spur Gears. Tribotest J., 5 (3), 1999: 225-250.

https://doi.org/10.1002/tt.3020050303

[18] A. Flodin, S. Andersson, Simulation of Mild Wear in Helical Gears. Wear, 241 (2), 2000: 123-128.

https://doi.org/10.1016/S0043-1648(00)00384-7

[19] A. Flodin, S. Andersson, A Simplified Model for Wear Prediction in Helical Gears. Wear, 249 (3-4), 2001: 285-292.

https://doi.org/10.1016/S0043-1648(01)00556-7

[20] A. Kahraman, P. Bajpai, N.E. Anderson, Influence of Tooth Profile Deviations on Helical Gear Wear. J. of Mechanical Design, 127 (4), 2005: 656-663.

https://doi.org/10.1115/1.1899688

[21] M. Kolivand, A. Kahraman, An ease-off based method for loaded tooth contact analysis of hypoid gears having local and global surface deviation. J. Mech. Des., 132 (7), 2010: 0710041-0710048.

https://doi.org/10.1115/1.4001722

[22] A. Pasta, G. Virzi Mariotti, Finite Element Method Analysis of a Spur Gear with a
Corrected Profile. J. Strain Analysis, 42, 2007: 281-292.

https://doi.org/10.1243/03093247JSA284

[23]A. Andreikiv, V. Panasyuk, M. Chernets, A theory of wear of materials in dry friction. Soviet Materials Science, 2, 1981: 153-158.

[24] M. Chernets, M. Pashechko, A. Nevchas, Methods of forecasting and increasing the wear resistance of tribotechnical sliding systems. In 3 volumes. Vol.1. Research and calculation of sliding tribosystems, methods to increase durability and wear resistance, Drogobich: KOLO, 2001 (in Ukrainian).

[25] M.V. Chernets., E. Kelbinski, R.Y. Jarema, Generalized method for the evaluation of cylindrical involute gears. Materials Science, 47, 2011: 45-51.

https://doi.org/10.1007/s11003-011-9366-9

[26] M.V. Chernets, Ju.M. Chernets, Evaluation of the strength, wear, and durability of a corrected cylindrical involute gearing, with due regard for the engagement conditions. J. of Friction and Wear, 37, 2016: 71-77.

https://doi.org/10.3103/S1068366616010050

[27] M. Chernets, Yu. Chernets, The Simulation of Influence of Engagement Conditions and Technological Teeth Correction on Contact Strength, Wear and Durability of Cylindrical Spur Gear of Electric Locomotive. Proc. IMechE Part J: J. of Engineering Tribology, 231(1), 2017: 57-62.

https://doi.org/10.1177/1350650116645024

[28] M.V. Chernets, S.V. Shil'ko, M.I. Pashechko, M. Barshch, Wear resistance of glass- and carbon-filled polyamide composites for metalpolymer gears. J. of Friction and Wear, 39 (5), 2018: 361-364.

https://doi.org/10.3103/S1068366618050069

[29] M. Chernets, Method of calculation of tribotechnical characteristics of the metalpolymer gear, reinforced with glass fiber, taking into account the correction of tooth. Eksploatacja i Niezawodnosc - Maintenance and Reliability, 21 (4), 2019: 546-552.

http://dx.doi.org/10.17531/ein.2019.4.2

[30] M. Chernets, M. Kindrachuk, A. Kornienko, A. Yurchuk, Experimental Estimation of Wear Resistance of Polyamide Composites, Reinforced by Carbon and Glass Fibres Used in Metal-Polymer Gearings. Acta Mechanica et Automatica, 14 (4), 2020: 206-210.

https://doi.org/10.2478/ama-2020-0029 